\title{
Gestão dos recursos minerais no município de Canaã dos Carajás - PA na perspectiva dos cidadãos
}

Management of mineral resourses in the municipality of Canaã dos Carajás-PA from the perspective of citizens

\author{
Poliana Bentes de Almeida ${ }^{1}$ \\ Simone Martins ${ }^{2}$ \\ Jones Nogueira Barros ${ }^{3}$ \\ Mauro Margalho Coutinho ${ }^{4}$
}

\begin{abstract}
Resumo:
Apesar de ser alvo de muitas críticas, a mineração é considerada uma atividade fundamental para o desenvolvimento socioeconômico dos países, visto que os minerais são essenciais para a vida do homem contemporâneo. Neste artigo propõe-se a realização de um estudo de caso para compreender se a gestão de atividades mineradoras em duas comunidades localizadas no entorno da cidade de Canaã dos Carajás, no estado do Pará são realizadas conforme as normas que regulamentam este setor. Nosso lócus de pesquisa foi composto pelas comunidades das vilas Feitosa e Ouro Verde. Ambas são próximas ao Complexo Eliezer Batista, conhecido como S11D. A partir de dados coletados por meio de entrevistas, pesquisa documental e observação direta e sistematizados com a utilização da técnica de análise de conteúdo, segundo o método seminal proposto por Bardin, foi constatada inexistência de diálogo entre a comunidade e a empresa mineradora e entre a comunidade e o Poder Público sobre a gestão dos recursos ambientais e financeiros. Conclui-se a necessidade de: tornar efetiva a gestão participativa; tonar os processos de tomada de decisões inclusivos, compreensíveis e transparentes para amenizar os impactos da atividade mineradora; melhorar os processos informacionais para com a sociedade para que ela possa auxiliar na proposição e acompanhamento de projetos que resultem em melhorias em sua qualidade de vida.
\end{abstract}

\footnotetext{
1 Doutoranda em Administração pela Universidade da Amazônia, mestre em Gestão de Conhecimento para o Desenvolvimento Socioambiental pela Universidade da Amazônia. Membro do grupo de pesquisa ESCARLATE e GESDEL. Diretora Executiva do Sindicato das Indústrias Minerais do Estado do Pará. Conselheira Administrativa da Companhia de Desenvolvimento Econômico do Pará. https://orcid.org/0000-0001-8622-4061. E-mail: polibentes@gmail.com

2 Professora da Universidade Federal de Viçosa. pós-doutorado em Administração pela Universidade Federal de Santa Catarina, Doutora em Administração pelo Centro de Pós-Graduação e Pesquisas em Administração da Universidade Federal de Minas Gerais, mestre em Administração pela Universidade Federal de Viçosa. Pesquisadora do IPPDS, GEGOP e GESDEL. https: / /orcid.org/0000-0002-6614-4811. E-mail: simone.m@ufv.br

3 Doutorado em Administração pela Universidade da Amazônia, Mestrado em Gestão e Desenvolvimento Regional pela Universidade de Taubaté. Docente do PPAD - Programa de Pós Graduação em Administração da Universidade da Amazônia. Membro do Grupo de Pesquisa em Gestão Social e do Desenvolvimento Local (GESDEL). http://orcid.org/0000-0001-7246-8938. E-mail: jonesbarros1@hotmail.com

4 Professor of the Business Administration Graduate Program (PPAD) at UNAMA. University of Amazon - UNAMA, Belém - PA - Brazil. PhD Telecom Engineering / MSc Computer Science. Research Group: (ESCARLATE) Ecologically smart and Solidary Cities - A Race before it's too LATE. http://orcid.org/0000-0002-4774-1661. E-mail: mauro.margalho@gmail.com
} 
Palavras-chave: Desenvolvimento Sustentável; Empreendimento Minerário; Mineração; Responsabilidade Social Corporativa.

\begin{abstract}
:
Despite being the target of much criticism, mining is considered a fundamental activity for the socioeconomic development of countries, since minerals are essential for the life of contemporary man. This article proposes to carry out a case study to understand if the management of mining activities in two communities located around the city of Canaã dos Carajás, in the state of Pará, are carried out in accordance with the rules that regulate this sector. Our research locus consisted of the communities of Feitosa and Ouro Verde villages. Both are close to the Eliezer Batista Complex, known as S11D. From data collected through interviews, documentary research and direct observation and systematized using the technique of content analysis, according to the seminal method proposed by Bardin, it was found that there was no dialogue between the community and the mining company and between the community and the government on the management of environmental and financial resources. It concludes the need to: make participatory management effective; make decision-making processes inclusive, understandable and transparent to mitigate the impacts of mining activity; improve information processes for society so that it can help propose and monitor projects that result in improvements in their quality of life.
\end{abstract}

Keywords: Sustainable Development; Mining Enterprise; Mining; Corporate social responsibility.

\title{
1. Introdução
}

Segundo Farias (2002), a mineração é considerada como uma atividade fundamental para o desenvolvimento econômico e social de muitos países, tendo em vista que os minerais são essenciais para a vida moderna. Contudo, é imprescindível que essa atividade seja realizada de maneira a promover também a melhoria da qualidade de vida da comunidade na qual está inserida e a preservação ambiental.

Os impactos ambientais e sociais adversos do território devem ser alvo de controle direto (empreendedor) e indireto (órgãos ambientais e partes interessadas). O cumprimento da legislação e dos processos de licenciamento ambientais, também referenciado na literatura como complience, são fundamentais para o controle e a minimização de tais impactos (JEBER; PROFETA, 2018). Destaca-se a mineração, sobretudo os grandes empreendimentos, como impulsionadores do desenvolvimento local, gerando um impacto significativo na população do entorno.

O Pará tem grande relevância histórica na atividade mineradora dentre os estados brasileiros. Isso vem ocorrendo desde o século XVII, com os diamantes de Itupiranga, no rio Tocantins, sudeste do estado, fato que, na década de 1960, representou um marco histórico para a mineração nacional e mundial, com a descoberta de Carajás, em junho de 1967, pelo geólogo Breno Augusto dos Santos. A importância do estado deve se manter assim no futuro, em função da gama de recursos minerais em seu subsolo. Além disso, possui riquezas em termos de biodiversidades, com destaque as características físicas, alto potencial hídrico e importante atributo socioeconômico (SILVA, 2012). 
Dados divulgados pelo Sindicato das Indústrias Minerais do Estado do Pará - SIMINERAL, em 20212, apontam o estado do Pará com o primeiro lugar no ranking das exportações minerais do Brasil no ano de 2020 , com $38 \%$ de participação no volume de exportação, correspondendo mais de US $\$ 18,000$ bilhões. No mesmo ano, a Agência Nacional de Mineração - ANM, revelou que o Pará foi o maior arrecadador da Compensação Financeira pela Exploração de Recursos Minerais do Brasil - CFEM - com 51,2\%. Nesse contexto, os municípios de Parauapebas e Canaã dos Carajás despontam no cenário brasileiro como os maiores arrecadadores, representando $45 \%$ da CFEM (DIÁRIO DO PARÁ, 2021).

Apesar dos benefícios trazidos pela atividade minerária, a coexistência da mineração com o meio social e ambiental pode não ser pacífica, pois este tipo de atividade pode provocar uma série de impactos ambientais indesejáveis e competição de espaço territorial (TANNO; SINTONI, 2003).

A herança histórica das técnicas minerárias rudimentares desde o Brasil Colônia, as ações de garimpos irregulares que destroem o ambiente e até mesmo falsos empresários que trabalham à margem da lei são fatores que abrem espaço para que o cidadão possa ter uma percepção equivocada da mineração.

Uma das calamidades com maior impacto e que mais afeta a imagem da indústria de mineração é referente ao rompimento de barragens, com vários casos ao redor do mundo, inclusive no Brasil, como o caso emblemático da Samarco em Mariana (COSTA, 2015) e o de Brumadinho, da Vale (EL PAIS, 2019). Embora bons estudos científicos tenham sido desenvolvidos no que diz respeito a impactos gerados por empreendimentos minerários nas últimas décadas (VANCLAY, 2002; MANCINI; SALA, 2018), há um número reduzido desses estudos focados na percepção de impactos de empresas pela comunidade em relação a projetos de mineração e a influência no processo de identificação e priorização destes. Com isso, as discussões acadêmicas sobre o assunto são de fundamental importância no cenário econômico e ambiental do Brasil, fazendo com que surja a oportunidade de novos aportes científicos a partir de diferentes enquadramentos sociais.

Verifica-se, nos últimos trinta anos, com a promulgação da Constituição brasileira de 1988 e a evolução do arcabouço legal ambiental, seja a nível federal, estadual ou municipal, em constante ajustes, como as espécies normativas que buscam regular a atividade, não apenas no sentido de permitir ao Estado o exercício da sua função de coordenação e controle, mas com a preocupação de que fossem adotadas práticas que possibilitassem o incremento da atividade dentro de padrões sustentáveis.

Como contribuição no sentido de suprir em alguma medida a lacuna deixada na academia, com este estudo se busca responder a seguinte pergunta: A gestão de atividades mineradoras localizadas no entorno da cidade de Canaã dos Carajás (PA) é realizada conforme as normas que regulamentam este setor?

É importante evidenciar que a finalidade deste trabalho não foi mensurar os impactos decorrentes da atividade mineradora, mas de analisar a percepção socioambiental e de gestão participativa na atividade mineral. O que se busca é compreender se na percepção dos cidadãos o tipo se a gestão praticada está em consonância com as exigências legais para este tipo de atividade.

A pesquisa se mostra relevante, pois irá contribuir para a promoção de ações de responsabilidade socioambientais em benefício das comunidades circunvizinhas aos empreendimentos minerários, as empresas promoverão uma espécie de relacionamento simbiótico que possibilitará conscientização coletiva, quer das organizações minerárias, quer das comunidades, preservando os recursos naturais, a mobilização para a cidadania plena e o desenvolvimento sustentável.

Metodologicamente caracteriza-se por ser uma pesquisa qualitativa, realizada por meio de um estudo de caso, por intermédio de entrevista semiestruturada, com dezoito atores-chave das comunidades de Vila de Ouro Verde e Vila Feitosa, grupos sociais vulneráveis na área de influência direta do empreendimento "Complexo S11D Eliezer Batista" localizado do município de Canaã dos Carajás no Estado do Pará. A interpretação dos dados foi feita mediante a análise de conteúdo proposta por Bardin (2016), que estabelece 
três fases: pré-análise, exploração do material e tratamentos dos resultados. A análise de conteúdo das entrevistas foi realizada com o auxílio do software ATLAS.ti.8, o que permitiu determinar as categorias mais relevantes.

Por meio deste tipo de pesquisa é possível evidenciar os resultados dos programas analisados e identificar as carências das comunidades, propondo-se ações que de fato possam contribuir para a tomada de decisão e criação de soluções em prol da população que vive no entorno do empreendimento minerário.

O artigo está estruturado em quatro partes, sendo além desta introdução e da conclusão. A primeira e segunda são destinadas ao quadro teórico que embasa a análise do problema proposto, com destaque para alguns conceitos fundamentais, a exemplo da indústria de mineração e gestão participativa. Na terceira parte discorre-se sobre a metodologia, indicando as ferramentas utilizadas na coleta de dados, delineamento Estudo de Caso e lócus da pesquisa. Na quarta é apresentada uma breve história social das comunidades em estudo, com base nos documentos oficiais e estudos realizados, a realidade de Canaã dos Carajás ao longo dos anos, após a instalação de empreendimento minerário. Na quinta e última parte são analisados os efeitos das ações dos programas socioambientais junto às comunidades envolvidas, com base na percepção da atividade mineral mineração e gestão dos recursos minerais.

\section{O cenário da Indústria de Mineração na sociedade}

A trajetória da atividade minerária no Brasil remonta ao período colonial, caracterizando-se nos seus primórdios como uma atividade extrativista bastante rudimentar. Ao longo da história, essa atividade evoluiu e se modernizou, alcançando um papel de destaque nacional e internacional no setor da mineração (JEBER; PROFETA, 2018). A atividade é regulamentada pelo sistema de concessão mineral brasileiro, cujo controle é realizado pela Agência Nacional de Mineração - ANM, do Ministério de Minas e Energia - MME, em consonância com o licenciamento ambiental executado pelos órgãos estaduais, distrital e federal de meio ambiente (Lei Estadual n 5.887, de 9 de maio de 1995, e na Lei Federal $n^{\circ} 6.938 / 91$ ).

A contribuição econômica da atividade extrativista para a economia global é amplamente reconhecida uma vez que estes permeiam quase a totalidade de produtos e serviços considerados essenciais (MANCINI; SALA,2018). A crescente demanda e o consequente aumento na produção dos recursos minerais implicam, não só no desenvolvimento econômico das regiões produtoras, como também impõe o desafio de garantir que esta atividade seja exercida com responsabilidade social e ambiental, considerando que a atividade produtiva pode e deve contribuir para a melhoria da qualidade de vida da sociedade atual e futura.

A literatura dominante aborda sobre a real efetividade do papel da mineração para o desenvolvimento dos espaços territoriais onde ela ocorre. Por se localizarem na maioria dos casos em uma região com poucas vocações econômicas (ANDRADE, 2001), a presença da atividade mineral poderia ter um impacto mais relevante para a dinâmica econômica local. No entanto, Andrade (2001), ao analisar dos indicadores de desenvolvimento humano, concluiu que não há uma relação entre a presença da atividade mineral com melhoria das condições de vida da população local.

Furtado (1969) e Hirschman (1977) afirmam que a mineração pode ter potencial para o desenvolvimento local se for adequadamente tributada e os recursos provenientes dessa tributação aplicados em prol da comunidade. Fernandes, Lima e Teixeira (2007), entretanto, classificam como insuficientes as obrigações legais impostas às grandes empresas mineradoras (tributos e licenças para operar) e defendem maior interação empresa- comunidade para aprimorar os mecanismos de desenvolvimento local. Para Enriquez (2007), a mineração pode ser considerada uma atividade sustentável se ela garantir o bem-estar das gerações futuras, o que pode ser feito a partir do uso sustentado das rendas que a mineração proporcionou. 
Vale destacar que a Constituição Federal de 1988 deu um novo balizamento às atividades minerais no Brasil com relação ao pagamento de tributos e rendas. A extinção do Imposto Único sobre a atividade Mineral IUM pela Carta Magna, fez com que a mineração passasse a ser tributada de forma idêntica às outras atividades econômicas, e a criação da Compensação Financeira pela Exploração de Recursos Minerais CFEM foram as principais inovações.

De acordo com Enríquez (2007) o royalty mineral - CFEM - é um pagamento pelo uso de um bem que pertence ao Estado, ou seja, é uma contraprestação e não um tributo. As receitas devem ser aplicadas, por estados e municípios, em projetos que revertam em benefícios da comunidade local, seja em melhoria da infraestrutura, da qualidade ambiental, da saúde ou educação.

Contudo, a atuação do setor minerário divide opiniões e figura como uma das temáticas mais debatidas nos últimos anos. Segundo Gaviria (2015), as condições econômicas favoráveis à expansão dos processos de acumulação capitalista de base mineradora têm levado ao aumento de conflitos com as populações locais, que, por vezes, defendem seus direitos e reclamam maior poder sobre seus territórios.

A partir de estudos de caso empíricos, Franks et al. (2014) identificaram os conflitos mais comuns que surgem em áreas de mineração, destacando-se os conflitos em torno de impactos ambientais, da saúde da comunidade e da distribuição justa dos recursos gerados. Além disso, os autores mostram a relação destes conflitos com o aumento de custos de implementação e operação de projetos, incluindo modificações em projetos, paradas na operação e perda de valor no mercado.

De modo a reduzir os impactos negativos e maximizar os benefícios gerados com a atividade mineradora, as empresas devem aperfeiçoar suas abordagens na avaliação de risco e no impacto social. Na obra "Licença Social para Operar e Avaliação de Impacto Social - Confiança e Engajamento das Comunidades Anfitriãs", a autora Santiago (2019) diz que o impacto social é um processo complexo, que apresenta uma relação causa-efeito, variável temporal, um enfoque processual, podendo ser positivo ou negativo, de primeira ou de segunda ordem, e importante tanto para o indivíduo, quanto para as organizações. É nesse contexto geral que a "aprovação" das comunidades se tornou de importância para as empresas.

No livro, Santiago (2019) traduz a vontade de buscar o conhecimento e inovação no relacionamento corporativo-comunitário por meio da Licença Social, é um conceito amplo, que nasceu em 1996, no Canadá, e atualmente é bastante utilizado no ambiente de negócios. Pode-se entender a Licença Social para Operar como uma abordagem conceitual que uma organização aplica no envolvimento com as comunidades e partes interessadas, auxiliando na identificação de ações proativas que as empresas podem tomar para aumentar a probabilidade de que elas irão desfrutar do apoio das comunidades onde trabalham (Jijelava \& Vanclay, 2014).

A licença social não é uma ferramenta ou abordagem isolada. É um movimento relacional que a empresa mantém com as comunidades vizinhas. Sua manutenção necessita, segundo Santiago (2019), da criação de um ambiente favorável e condições adequadas para assegurar a confiança da população onde se opera.

Ressalta-se a importância do compartilhamento dos valores advindos dos projetos, mediante uma perspectiva que considere os anseios e necessidades das comunidades locais, privilegiando a transparência e o fortalecimento do diálogo entre as partes interessadas e as parcerias público-privada-comunitárias. Por isso, é condição "sine qua non" para que mineradoras mantenham investimento constante em programas de cunho social. Esse tem sido o caso daquelas que atuam no estado do Pará, uma das regiões produtoras mais expressivas da mineração brasileira.

Neste sentido, não se pode imaginar uma gestão da atividade mineradora sem a participação da sociedade. Ainda que a gestão da atividade mineradora seja de competência da iniciativa privada, na maioria dos casos, com as normas instituídas, esta também precisa ser transparente e democrática. 


\section{A Gestão Participativa dos recursos naturais}

O setor mineral encontra-se inserido em um contexto onde se espera das empresas que elas contribuam de alguma maneira efetiva para alavancar o desenvolvimento econômico, social e ambiental. Por isso, cobra-se, cada vez mais, a integração das concepções do desenvolvimento sustentável nas práticas organizacionais que se conectam com a indústria mineral.

Promulgada em 1988, após mais de duas décadas de Governo Militar, a Constituição Federal é o marco do processo de consolidação da democracia no Brasil. A carta magna que garantiu ao cidadão uma série de direitos outrora cerceados ficou conhecida como a Constituição Cidadã. Para PIOVESAN (2000), a partir da Constituição de 1988, há uma redefinição do Estado brasileiro, bem como dos direitos fundamentais. Em seu preâmbulo, a Carta de 1988 define a instituição de um Estado democrático: "destinado a assegurar o exercício dos direitos sociais e individuais, a liberdade, a segurança, o bem-estar, o desenvolvimento, a igualdade e a justiça como valores supremos de uma sociedade fraterna, pluralista e sem preconceitos [...]. Dentre os princípios que alicerçam o Estado brasileiro destacam-se a cidadania e a dignidade da pessoa humana conforme previsto no artigo $1^{\circ}$, incisos II e III.

Para Dallari (1996), a participação popular prevista na Constituição Federal de 1988 é um princípio inerente à democracia, garantindo aos indivíduos, grupos e associações, o direito não apenas à representação política, mas também à informação e à defesa de seus interesses. Possibilita-lhes, ainda, a atuação e a efetiva interferência na gestão dos bens e serviços públicos.

Neste sentido, a gestão dos recursos naturais é um dos componentes essenciais do processo de regulação das inter-relações entre os sistemas socioculturais e o meio ambiente biofísico (VIEIRA; WEBER, 2000; GODARD, 2002). Destaca-se que ela abrange a diversidade de representações dos atores sociais e a variedade nas diferentes escalas espaciais (do local ao global) e temporais (do curto ao longo prazo).

Para tanto, a gestão participativa dos recursos naturais configura-se como uma ação importante no estabelecimento mais harmônico entre a sociedade e o meio ambiente, buscando compromissos diversos de atuação coletiva, seja no âmbito da sociedade civil ou pública (VIEIRA, 2005).

A democratização dos processos decisórios de vários segmentos das políticas nacionais e regionais dos países desenvolvidos vem estimulando cada vez mais a formação de parcerias e, principalmente, a participação mais ampla da sociedade nesses processos. McALLISTER (1998), destaca que os processos de consulta pública, denominados de abordagens participativas (multistakeholder approach), são metodologias muito apropriadas para delinear a visão e as metas de gestão de recursos naturais.

MITCHELL (1997), lembra que modelos participativos, onde as comunidades que irão ser afetadas por determinadas políticas ou empreendimento são ouvidas, facilitam planos e projetos, pois:

- Definem-se os problemas mais efetivamente;

- Tem-se acesso a informações e entendimentos ausentes nas abordagens meramente científicas;

- Identificam-se soluções alternativas socialmente aceitáveis; e

- Cria-se um senso de cooperação que facilita a implementação do plano ou projeto.

Em vista da abordagem participativa privilegiar o processo de tomada de decisão por consenso, é interessante citar os princípios da proposta de CORMICK et al. (1996) sobre sua construção, com vistas ao desenvolvimento sustentável. O processo de obtenção do consenso deve ser:

- Voltado a propostas definidas; 
- Inclusivo e não exclusivo com relação a participantes;

- Proporcionar participação voluntária;

- Sua organização é construída pelas partes envolvidas;

- Deve ter flexibilidade;

- Deve dar oportunidades iguais de participação;

- Respeitar a diversidade de interesses;

- Demonstrar senso de responsabilidade;

- Ter limites de duração; e

- Preocupar com acordos passíveis de implementação.

Diante disto, conceber orientações para um desenvolvimento capaz de equilibrar demandas econômicas, ambientais e sociais, é uma tarefa desafiadora, complexa e marcada por muitos debates e divergências (BERARDI, 2012). Essas pressões ganharam força nas últimas décadas e seus reflexos podem ser observados em marcos históricos e institucionais no mundo.

A Declaração sobre Direito ao Desenvolvimento - adotada pela Resolução n. 41/128, da Assembleia Geral das Nações Unidas (1986), diz que o desenvolvimento é um processo econômico, social, cultural e político abrangente, que visa o constante incremento do bem-estar de toda a população e de todos os indivíduos com base em sua participação ativa, livre e significativa no desenvolvimento e na distribuição justa dos benefícios daí resultantes.

Segundo Sen (2010), o desenvolvimento pode ser visto como um processo de expansão das liberdades reais que as pessoas desfrutam. O crescimento do Produto Interno Bruto - PIB ou das rendas individuais pode ser muito importante como um instrumento para ampliar as liberdades usufruídas pela sociedade. Contudo, as liberdades dependem também de outros motivadores, como as medidas sociais e econômicas, tais como os serviços de educação e saúde, e os direitos civis, a liberdade de participar de discussões e informações públicas.

A ideia de sustentabilidade ou de desenvolvimento sustentável, que começou ancorada em grande parte na preocupação ambiental, acabou por envolver as dimensões econômica e social a partir dos anos 1990, e criou uma ligação com a ideia de responsabilidade social empresarial, em que as empresas passaram a ser cobradas a desenvolver práticas que vão além da geração dos lucros e do cumprimento das leis, devendo ser, também, geradoras de ações responsáveis a longo prazo (LEMOS et al., 2006).

A empresa ser socialmente responsável por suas ações é a nova diretriz, que reúne o exercício da política e se inclui na quebra de paradigmas, englobando assuntos coletivos ao se incorporar nas questões do meio ambiente, da educação, dos segmentos empobrecidos, enfim, num horizonte de cunho social, alavancando a reputação da empresa e sua competitividade. Para Sen (2000), com oportunidades sociais adequadas, os indivíduos podem efetivamente moldar seu próprio destino e ajudar uns aos outros. Não precisam ser vistos, sobretudo, como beneficiários passivos de engenhosos programas de desenvolvimento.

\section{Metodologia}

Para alcançar o objetivo proposto com este estudo, sobre os programas socioambientais no setor mineral, optou-se por utilizar uma abordagem qualitativa de modo a oferecer ao leitor uma visão mais ampla sobre o 
tema. Segundo Richardson et al. (1999), a abordagem qualitativa procura descrever a complexidade de determinado problema, analisar a interação de certas variáveis, compreender e classificar processos dinâmicos vividos pela organização e entender particularidades do seu comportamento.

Entende-se que devido à peculiaridade do problema de pesquisa - qual a percepção das comunidades sobre a atividade mineral? - , uma abordagem meramente quantitativa não seria suficiente, considerando que somente indicadores objetivos poderia desprestigiar a subjetividade nas análises realizadas.

Como técnica de pesquisa utilizou-se o estudo de caso que deu-se em função da necessidade de se investigar um fenômeno social complexo, permitindo compreender a dinâmica apresentada dentro de contextos específicos. Considerando a importância da singularidade no processo de escolha do estudo de caso, a seleção do território analisado se justifica por se tratar da maior província mineral do Brasil e pelo fato do empreendimento ser maior projeto de minério de ferro da história da Vale e da mineração no mundo.

O universo de pesquisa foram as duas comunidades, Vila Feitosa e Vila Ouro Verde, consideradas como grupos sociais vulneráveis na área de influência direta do empreendimento "Complexo S11D Eliezer Batista" no município de Canaã dos Carajás (sul do Estado do Pará).

Destacam-se nessa pesquisa o uso da análise documental, observação direta e, entrevistas com roteiro semiestruturado. Foram feitas duas visitas in-loco, em julho de 2019 foi realizada a observação direta ao município e nas comunidades vizinhas ao projeto, com o intuito de se aproximar e obter uma visão geral da localidade impactada pelo projeto e ao município. Em outubro de 2019 foram conduzidas as entrevistas semiestruturadas com os atores-chave das comunidades vizinhas ao projeto.

Como método de pesquisa utilizou-se a análise documental, que teve como objetivo entender o contexto histórico, político, social e econômico do município e da região onde está instalado o empreendimento mineral, além de levantar dados sobre o processo de extração do minério. A análise incluiu elementos internos da empresa, como relatórios de Sustentabilidade, Relatórios de Desempenho Ambiental, Sistema de Gestão de Stakeholder, e documentos públicos de múltiplas fontes. A periodização do estudo foi estabelecida entre os anos 2013 a 2019 para artigos científicos, utilizando-se as bases de dados de bibliotecas eletrônicas e o mesmo período para documentos oficiais, em que também se optou em busca na literatura cinzenta, base de dados do Google Acadêmico.

Para a realização das entrevistas com as comunidades foram feitos contatos com a empresa, que demonstrou interesse e disponibilidade ao longo do processo. Esta informou que cada vila tem uma associação de moradores e foi feito o contato com os líderes dessas para que tomassem conhecimento, com antecedência, dos objetivos da pesquisa. Com o apoio dos líderes teve como ponto inicial a identificação e análise dos atores sociais que poderiam contribuir para a compreensão dos impactos. Sendo assim, nas comunidades selecionadas foi realizada a coleta de dados, por meio de entrevistas semiestruturadas, com os atores-chave, e teve como foco antigos moradores da comunidade, a fim de ter uma prospecção longitudinal dos impactos advindos da mineração, o que possibilitou uma visualização geral do auxílio prestado nas duas comunidades (Vila Ouro Verde e Vila Feitosa) e na compreensão da trajetória de vida, totalizando 18 entrevistas, conforme quadro 1, que foram gravadas e posteriormente transcritas.

Quadro 1 - Distribuição das variáveis referentes aos dados sociodemográficos dos entrevistados da Vila Feitosa e Vila Ouro Verde, Canaã dos Carajás, Pará

\begin{tabular}{|c|c|l|l|c|c|}
\hline Identificação & Sexo & \multicolumn{1}{|c|}{ Idade } & Escolaridade & $\begin{array}{c}\text { Renda familiar } \\
\text { (salário mínimo) }\end{array}$ & $\begin{array}{c}\text { Tempo de } \\
\text { residência } \\
\text { (anos) }\end{array}$ \\
\hline E01 & M & De 41 a 60 anos & Analfabeto & Menos de 1 & 34 \\
\hline E02 & F & De 41 a 60 anos & $\begin{array}{l}\text { Ensino Fundamental } \\
\text { Incompleto }\end{array}$ & Menos de 1 & 34 \\
\hline
\end{tabular}




\begin{tabular}{|c|c|c|c|c|c|}
\hline E03 & $\mathrm{M}$ & De 41 a 60 anos & $\begin{array}{l}\text { Ensino Fundamental } \\
\text { Incompleto }\end{array}$ & 1 a 5 & 3,5 \\
\hline E04 & M & De 41 a 60 anos & $\begin{array}{l}\text { Ensino Fundamental } \\
\text { Completo }\end{array}$ & 1 a 5 & 25 \\
\hline E05 & M & De 41 a 60 anos & $\begin{array}{l}\text { Ensino Médio } \\
\text { Completo }\end{array}$ & 1 a 5 & 14 \\
\hline E06 & $\mathrm{M}$ & De 21 a 40 anos & $\begin{array}{l}\text { Ensino Médio } \\
\text { Incompleto }\end{array}$ & 1 a 5 & 39 \\
\hline E07 & $\mathrm{M}$ & De 41 a 60 anos & $\begin{array}{l}\text { Ensino Médio } \\
\text { Incompleto }\end{array}$ & 1 a 5 & 42 \\
\hline E08 & $\mathrm{F}$ & De 21 a 40 anos & $\begin{array}{l}\text { Ensino Médio } \\
\text { Completo }\end{array}$ & 1 a 5 & 36 \\
\hline E09 & M & De 61 a 80 anos & $\begin{array}{l}\text { Ensino Fundamental } \\
\text { Incompleto }\end{array}$ & 1 a 5 & 31 \\
\hline E10 & $\mathrm{F}$ & De 61 a 80 anos & $\begin{array}{l}\text { Ensino Fundamental } \\
\text { Incompleto }\end{array}$ & 1 a 5 & 25 \\
\hline E11 & $\mathrm{M}$ & De 41 a 60 anos & Ensino Fundamental & 1 a 5 & 34 \\
\hline E12 & $\mathrm{M}$ & De 41 a 60 anos & Ensino Médio & 1 a 5 & 13 \\
\hline E13 & $\mathrm{M}$ & De 41 a 60 anos & Ensino Superior & 1 a 5 & 34 \\
\hline E14 & $\mathrm{M}$ & De 41 a 60 anos & Ensino Fundamental & 1 a 5 & 34 \\
\hline E15 & $\mathrm{M}$ & De 61 a 80 anos & $\begin{array}{l}\text { Ensino Fundamental } \\
\text { Incompleto }\end{array}$ & Não sabe & 30 \\
\hline E16 & M & De 61 a 80 anos & $\begin{array}{l}\text { Ensino Fundamental } \\
\text { Incompleto }\end{array}$ & 1 a 5 & 25 \\
\hline E17 & $\mathrm{F}$ & De 41 a 60 anos & Ensino Médio & 1 a 5 & 24 \\
\hline E18 & $\mathrm{F}$ & De 41 a 60 anos & Ensino Superior & 1 a 5 & 25 \\
\hline
\end{tabular}

Fonte: Elaboração própria (2020).

O município de Canaã dos Carajás, ilustrado na Figura 1, teve início a partir de um assentamento agrícola. O Projeto de Assentamento Carajás, localizado na região sudeste do Pará, foi implantado em 1982. Em outubro de 1994, por meio da Lei Estadual 5.860, Centro de Desenvolvimento Regional - CEDERE foi desmembrado de Parauapebas e virou o município de Canaã dos Carajás. O nome tem origem bíblica e faz referência à terra prometida por Deus ao seu povo. Sua população estimada em 2019, é de 37.085 habitantes, conforme dados do Instituto Brasileiro de Geografia e Estatística (IBGE, 2018).

Figura 1 - Mapa da Localização do Município de Canaã dos Carajás. Pará

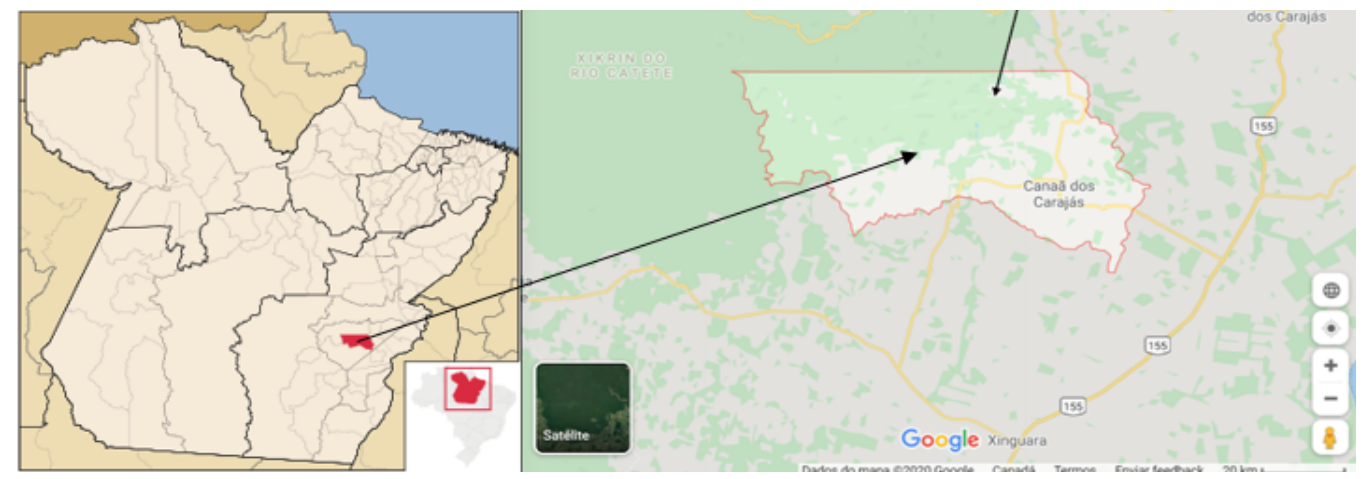

Fonte: Adaptado pela autora a partir do Google Maps (2020).

Na década de 90, Canaã dos Carajás tinha uma formação basicamente agropecuária no fim do milênio, com a descoberta de jazidas minerais de cobre, níquel e ferro no município. Explorando o cobre, a mina de 
Sossego foi a primeira a ser construída, com início de suas operações em 2003, e em 2013 iniciou-se a construção da mina de S11D, exploração de minério de ferro.

O texto constitucional estabeleceu que as jazidas e demais recursos minerais são pertencentes à União Federal, ficando sua exploração condicionada à autorização ou concessão. Assim, os entes políticos federados que tiverem seus recursos explorados receberão a Compensação Financeira pela Exploração Mineral - CFEM. Neste sentido, não poderia ser diferente com a cidade em questão.

Conforme dados da Agência Nacional de Mineração (2021), a arrecadação da CFEM em Canaã dos Carajás atingiu em $2004 \mathrm{R} \$ 5,346$ milhões, o que se elevou ainda mais nos últimos anos, alcançando em $2020 \mathrm{R} \$$ 1,198 Bilhão, ocupando o $2^{\circ}$ lugar no ranking nacional.

No último PIB divulgado pelo IBGE, relativo ao ano de 2018 , o setor indústria é responsável por $78 \%$ do PIB municipal, ocupando a $6^{a}$ lugar no ranking estadual e o $2^{\circ}$ lugar em se tratando do PIB per capita.

Atualmente, Canaã dos Carajás possui quatro vilas rurais próximas ao seu centro urbano: Vila Planalto, Vila Feitosa, Vila Ouro Verde e Vila Bom Jesus, sendo que para a análise desta pesquisa foram consideradas as comunidades afetadas diretamente indicadas na Figura 2 pelo empreendimento minerário Complexo Eliezer Batista S11D: Vila Ouro Verde e Vila Feitosa.

Figura 2 - Mapa de Localização do Complexo Eliezer Batista S11D, e vilas rurais Ouro Verde e Feitosa, Canaã, Pará

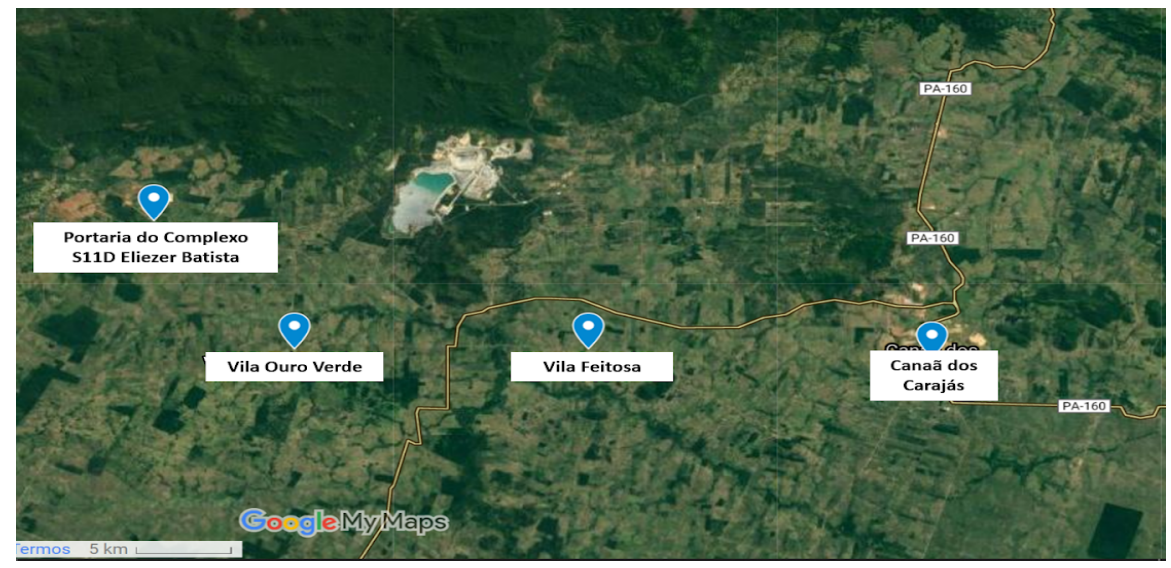

Fonte: Adaptado pela autora a partir do Google Maps (2020).

O quantitativo populacional da Vila Feitosa e Vila Ouro Verde, de acordo com dados retirados do Plano Local de Habitação de Interesse Social - PLHIS (PMCC, 2014), elaborado pela Secretaria Municipal de Saúde em parceria com a Vale S.A., é de 151 e 164 habitantes, respectivamente, e a agricultura que caracteriza a vida econômica de seus moradores.

\subsection{Análise de Conteúdo com apoio do software Atlas TI}

A Análise de Conteúdo foi utilizada neste artigo, visto que possibilita a explicitação e a sistematização do conteúdo das pesquisas a partir de índices passíveis de quantificação, bem como a elaboração de inferências e deduções lógicas e justificadas sobre o conteúdo das mensagens (BARDIN, 2016). 
Da mesma forma, a Análise de Conteúdo reconhece a integração dos métodos quantitativos e qualitativos, o que possibilita a associação dos resultados e a produção de interpretações fundamentadas. Nesse particular, Moraes (1999) afirma que a Análise de Conteúdo é:

[...] uma metodologia de pesquisa usada para descrever e interpretar o conteúdo de toda classe de documentos e textos. Essa análise, conduzindo a descrições sistemáticas, qualitativas ou quantitativas, ajuda a reinterpretar as mensagens e a atingir uma compreensão de seus significados num nível que vai além de uma leitura comum (MORAES, 1999, p. 8).

Bardin (2016) indica que a utilização da análise de conteúdo prevê três fases fundamentais: pré-análise, exploração do material e tratamento dos resultados - a inferência e a interpretação.

Neste caso, iniciou-se pelas entrevistas que foram transcritas e a seu agrupamento constitui o corpus da pesquisa. Para isto, foi preciso obedecer às seguintes regras Bardin (2016): de exaustividade (deve-se esgotar a totalidade da comunicação, não omitir nada); representatividade (a amostra deve representar o universo); homogeneidade (os dados devem referir-se ao mesmo tema, serem obtidos por técnicas iguais e colhidos por indivíduos semelhantes); pertinência (os documentos precisam adaptar-se ao conteúdo e objetivo da pesquisa) e exclusividade (um elemento não deve ser classificado em mais de uma categoria).

Devido à quantidade de dados que foram obtidos e à complexidade das interações de opiniões dos dois diferentes grupos de entrevistados, foi utilizado, para auxílio à análise de conteúdo e à ordenação conceitual, o software Atlas.ti - versão 8.0, aplicado à análise qualitativa de informações obtidas por meio de entrevistas. As gravações das entrevistas foram feitas em formato digital, transcritas com a utilização de um processador de textos e, finalmente, inseridas no Atlas TI.

A fase da exploração do material, que segundo Bardin (2016), consiste na exploração do material com a definição de categorias (sistemas de codificação) e a identificação das unidades de registro (unidade de significação a codificar corresponde ao segmento de conteúdo a considerar como unidade base, visando à categorização e à contagem frequencial) e das unidades de contexto nos documentos (unidade de compreensão para codificar a unidade de registro que corresponde ao segmento da mensagem, a fim de compreender a significação exata da unidade de registro).

Com o auxílio do software Atlas $\mathrm{TI}$, pode-se trabalhar o protocolo para gerar o código de análise, e foi considerado as seguintes categorias: social, ambiental e econômica, tendo em vista que o problema de pesquisa pretende, analisar a percepção da nas comunidades ao entorno no empreendimento sobre a gestão dos recursos da atividade mineral paraense. Nesse processo, representados no Atlas TI em códigos, são a unidade básica da análise, que estão relacionadas neste artigo as citações dos entrevistados das comunidades da Vila Feitosa e Vila Ouro Verde.

A terceira fase diz respeito ao tratamento dos resultados, inferência e interpretação. Esta etapa é destinada ao tratamento dos resultados; ocorre nela a condensação e o destaque das informações para análise, culminando nas interpretações inferenciais; é o momento da intuição, da análise reflexiva e crítica (BARDIN, 2016).

Tendo em vista as diferentes fases da análise de conteúdo proposta por Bardin (2016), destacam-se, como a própria autora o fez, as dimensões da codificação e categorização que possibilitam e facilitam as interpretações e as inferências; ou seja, foi comparada a existência de relação entre o que foi observado pela coleta e análise dos dados e o que foi suscitado nas questões norteadoras e objetivos da pesquisa, a 
partir dessas observações e conclusões. O resultado desta pesquisa será apresentado no item intitulado análise e discussão dos resultados.

\section{Análise e discussão dos resultados}

\subsection{O perfil socioeconômico dos atores sociais entrevistados}

A abordagem dos membros das comunidades de Vila Feitosa e Vila Ouro Verde, totalizando 18 (dezoito) entrevistados, apurou que $28 \%$ dos participantes da pesquisa são do sexo feminino e $72 \%$ pertencem ao sexo masculino, conforme Gráfico 1.

Gráfico 1 - Percentual do gênero dos participantes da pesquisa das comunidades de Vila Feitosa e Vila Ouro verde. Canaã dos Carajás, Pará

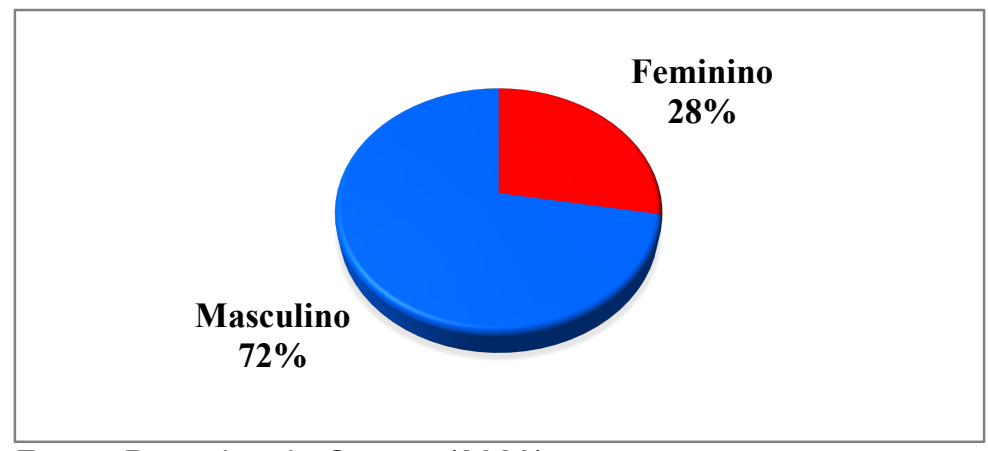

Fonte: Pesquisa de Campo (2020).

A predominância masculina entre os participantes da pesquisa pode estar ligada à disponibilidade ou a um reflexo da cultura desses grupos sociais tradicionais, em decorrência do patriarcalismo que é uma estrutura social de poder que institui uma desigualdade entre homens e mulheres, com os primeiros exercendo dominação sobre as segundas e estruturando sua ação no social.

Quanto à idade, identificou-se que $67 \%$ dos participantes com idade que varia entre 41 a 60 anos de idade, enquanto os $22 \%$ restantes possuem idade entre 61 a 80 anos e entre 21 e 40 anos (11\%), esboçadas no Gráfico 2.

Gráfico 2 - Percentual da média de idade dos participantes da pesquisa das comunidades de Vila Feitosa e Vila Ouro verde. Canaã dos Carajás, Pará 


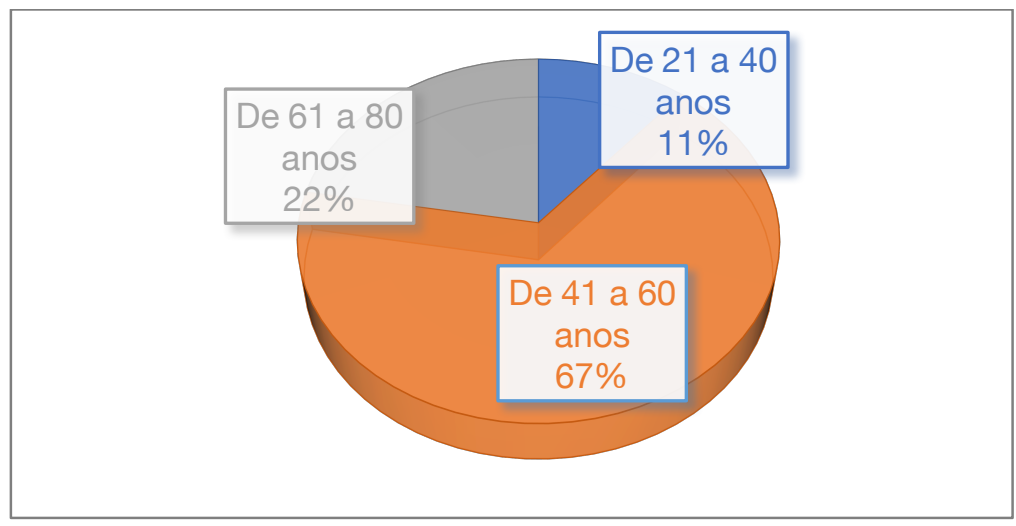

Fonte: Pesquisa de Campo (2020).

No Gráfico 3, pôde-se observar ser baixa a escolaridade formal dos membros das comunidades, considerando que 33\% declaram-se com Ensino Fundamental incompleto; 22\% informaram possuir Ensino Médio completo, 17\% com Ensino Fundamental completo, 11\% com Ensino Superior, 11\% com Ensino Médio incompleto e $6 \%$ analfabetos.

Gráfico 3 - Percentual da escolaridade dos participantes da pesquisa das comunidades de Vila Feitosa e Vila Ouro verde. Canaã dos Carajás, Pará

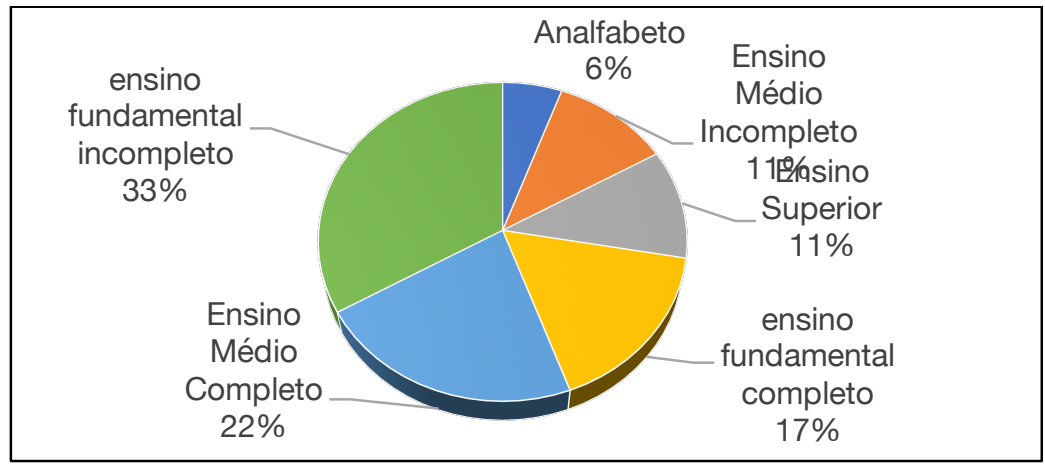

Fonte: Pesquisa de Campo (2020).

Em seguida, questionou-se a naturalidade, o tempo de residência no município e a situação do imóvel onde residem. Todos os entrevistados nasceram em outros municípios, mas fixaram moradia na região, $44 \%$ declaram morar nessas localidades à época do assentamento do Grupo Executivo das Terras do Araguaia e Tocantins (GETAT), ou seja, entre 35 a 40 anos; $39 \%$ moram entre 25 a 30 anos (desde a emancipação do município); $11 \%$ informaram morar entre 5 a 10 anos (etapa de implantação do Projeto Ferro Carajás S11D iniciou-se em agosto de 2013); outros 6\% disseram que moram na comunidade entre 15 a 20 anos (etapa de iniciou a montagem da estrutura do projeto sossego, extração do cobre, em 1999), sendo que todos declararam morar em imóvel próprio.

Conforme os dados do IBGE (Censo Demográfico, 2010), 40,5\% dos domicílios do município de Canaã dos Carajás, as famílias têm renda nominal mensal per capita de até 1/2 salário mínimo. Neste caso, a renda familiar de $83 \%$ dos entrevistados está entre 1 a 5 salários mínimos provenientes com o trabalho da agricultura e agropecuária, com a produção de trabalhos manuais, entre outras fontes de renda. 


\subsection{Percepção dos entrevistados sobre a mineração}

Com este item buscou-se compreender a percepção dos entrevistados sobre a atividade de mineração realizada em suas comunidades. Desse modo, com a primeira pergunta: "O que você entende por mineração?" observou-se que os entrevistados têm uma básica noção sobre o conceito de mineração, conceito esse que adquiriram na educação informal da vida.

Com o auxílio do Atlas TI foi elaborada "nuvens de palavras", onde importância de cada palavra está associada a seu tamanho ou cor, como mostra a Figura 3. Como pode ser o observado, a palavra "minério" aparece em destaque, ou seja, é uma palavra frequente.

Tendo em conta que essa visão da mineração focada apenas no minério é equivocada, pois para os padrões de vida contemporânea, a mineração torna-se essencial porque proporciona bem-estar social com serviços como transporte intermunicipal e estadual, assistência à saúde, fornecimento de energia elétrica e internet e dentre outros.

Essa informação é interessante, pois demonstra que o nível de entendimento das comunidades sobre a atividade mineral deve ter uma atenção nas próximas ações da empresa, pois requer canais adequados de participação, de transparência e de controle social.

Figura 3 - Nuvem de palavras "O que você entende por mineração?"

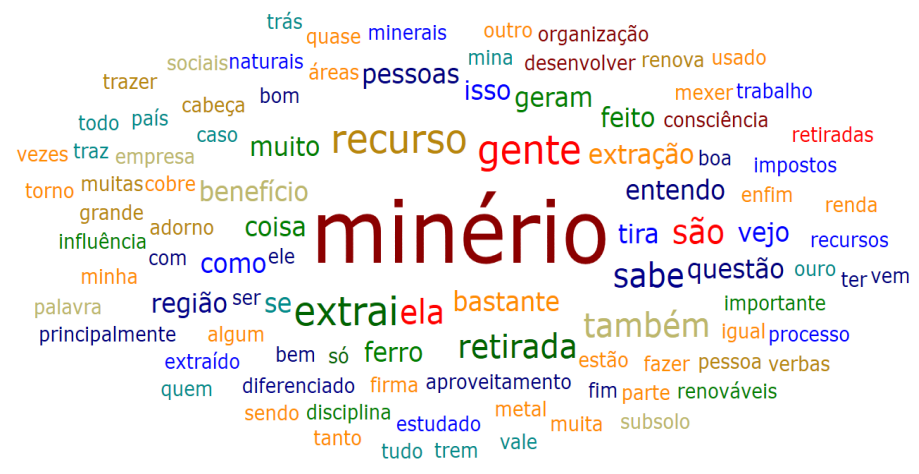

Fonte: Elaboração própria (2020).

Essa mesma constatação se repetiu quando foram questionados sobre o que eles entendiam por Desenvolvimento Sustentável, e demonstraram pouco entendimento sobre o conceito, por ser amplo e variado. Por meio do Atlas TI pode-se elaborar "nuvens de palavras", que sintetizou as respostas a essa questão, apresentada na Figura 4.

Figura 4 - Nuvem de palavras "O que você entende por Desenvolvimento Sustentável?" 


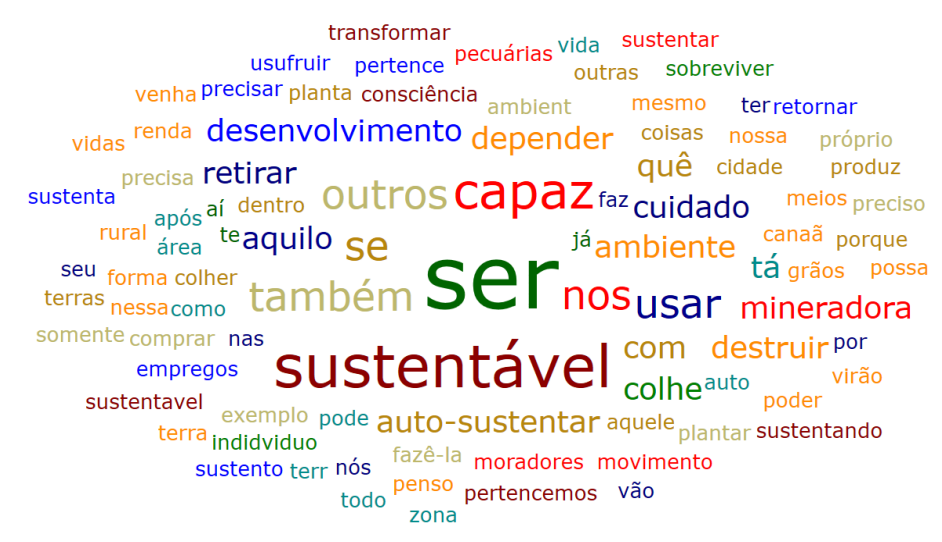

Fonte: Elaboração própria (2020).

Através da repetição das palavras como: colheita, sustento, terra, rural, alimentos e outras, percebe-se que esta visão de Desenvolvimento Sustentável está intimamente ligada a origem de colonização do munícipio, pois na década de 90, Canaã dos Carajás tinha uma formação basicamente agropecuária, onde colonos vindos de outras regiões vinham "ganhar a vida" por meio de cultivos e criações. Na época, a economia da cidade economia girava em torno da cultura do arroz, milho, feijão e na cadeia do leite e do gado de corte.

Na nuvem de palavras percebemos outras repetições como: destruir e retirar. Essa constatação está ligada a pratica do cuidado ao utilizar os recursos minerais para que o município construa um futuro promissor a partir de um modelo de desenvolvimento equilibrado e sustentável nos seus diversos aspectos - social, cultural, político, ambiental e econômico.

Ressalta-se que passados 26 anos de sua emancipação política e administrativa, Canaã dos Carajás surpreende, despontando dentre os municípios mais promissores do estado do Pará ocupando posição estratégica no âmbito da Região de Integração Carajás, por conta de suas riquezas minerais, a maioria ainda por explorar. Exatamente por conta disso se destaca como uma das cidades que apresenta o maior índice de crescimento populacional do Brasil.

\subsection{Percepção dos entrevistados sobre o s recursos financeiros da atividade de mineração}

Quando questionados se o município recebe algum tipo de benefício financeiro oriundo da mineração, $94 \%$ dos entrevistados afirmam ter conhecimento e outros $6 \%$ não têm, conforme Gráfico 4.

Gráfico 4 - Percentual do conhecimento sobre o recebimento de benefício financeiro da mineração ao município. Canaã dos Carajás, Pará 


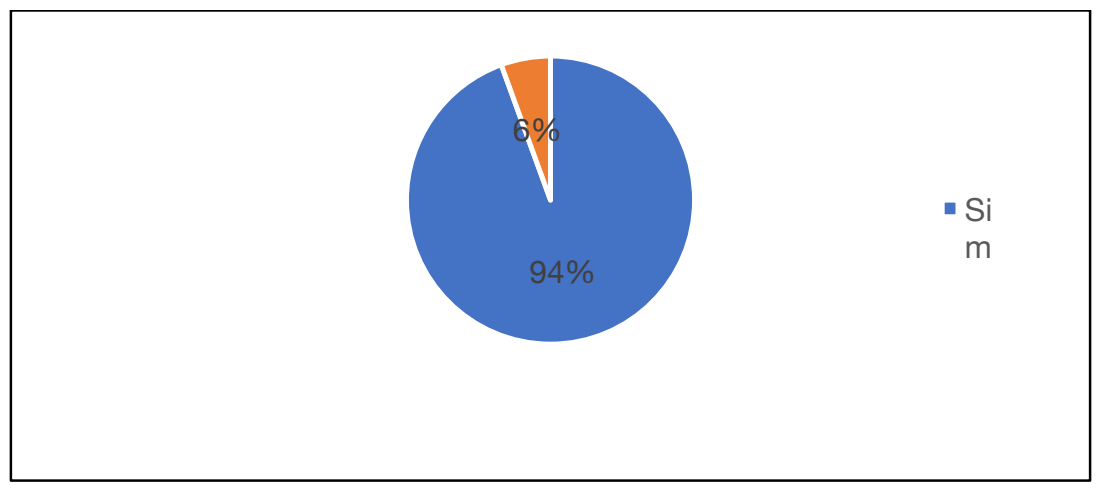

Fonte: Pesquisa de Campo. Elaboração própria (2020).

Sobre os royalties pagos pela atividade mineradora, os entrevistados demonstraram ter conhecimento deste benefício financeiro. Porém, cerca de $83 \%$, desconhecem sobre a existência de plano formalizado de aplicação dos recursos; sobre os critérios adotados para o uso desses recursos; existência de formas de participação direta da comunidade nos processos de tomada de decisões; ou se existe outros tipos de benefícios que o município recebe da atividade de mineração, conforme Quadro 1, a seguir:

\section{Quadro 1 - Depoimentos sobre aplicação dos recursos. Canaã dos Carajás, Pará}

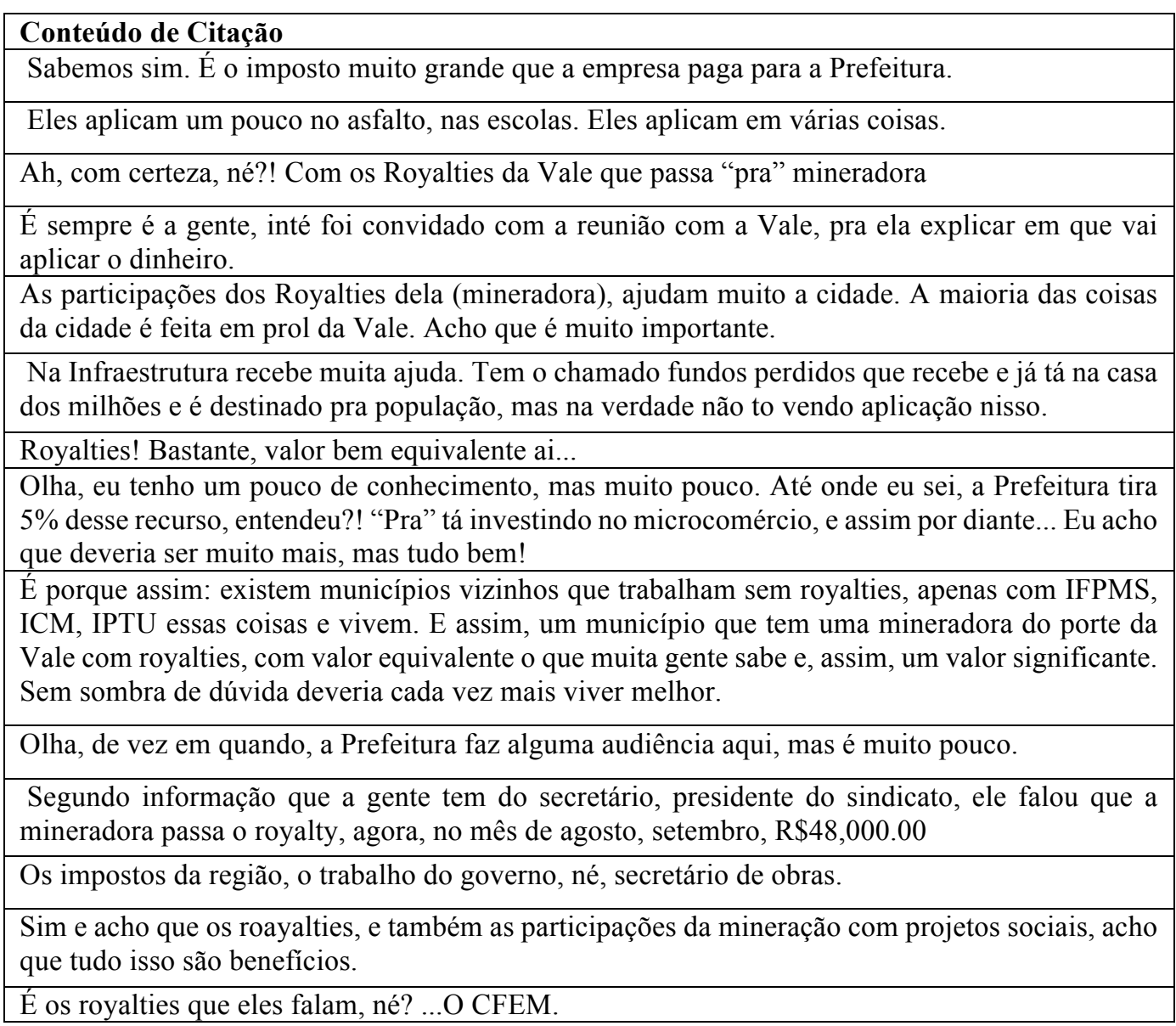


Olha a gente tem informação até mesmo do poder público, mas não informação assim diretamente, ne. A gente sabe que esse dinheiro é investido, principalmente mais em infraestrutura, né. Maior parte desse dinheiro é nisso. E tem também o fundo de desenvolvimento. O fundo que é da agricultura, né? Mas, por enquanto, não tá sendo muito, ainda, aplicado ainda. "Tão" gerando projetos pra saber como vai aplicar esse recurso ainda.

Diz que paga um royalty lá pro município.

Não. Pra mim não, não sei, nunca procuraram pra mim.

Mas só que a gente for falar, tem né? Agora eu não posso provar porque não fui. A gente tem que provar uma coisa que a gente viu com olho, né? Mais que a gente ver falar, ajuda né? Que eles recebem, né?

Ah, eu não posso falar um valor "X", porque às vezes alguém fala um valor de R\$ 30 Milhões, outros falam R\$ 20 Milhões, outros fala R\$ 15 Milhões. A gente não tem... Eu pelo menos não sei. Fiquei parada até aí que diz que era R\$30 Milhões mensal.

Fonte: Pesquisa de Campo. Elaboração própria (2020).

\subsection{Normativos e finanças da atividade de mineração no estado do Pará}

Conforme citado na seção 2, a CFEM é uma espécie de royalty pago pela empresa mineradora, e é regulamentada pela Lei $\mathrm{N}^{\circ} 13.540$ de dezembro de 2017, que alterou a base da cobrança, as alíquotas e a repartição da receita (BRASIL, 2017), e pelo Decreto $N^{\circ} 9.407$ de 2018 estabeleceu critérios para distribuição da parcela de $15 \%$ da CFEM entre os municípios impactados pela mineração e infraestruturas (BRASIL, 2018).

Atualmente, os principais tributos e encargos que incidem sobre a mineração são:

$\checkmark \quad$ Imposto de Renda - Pessoa Jurídica;

$\checkmark \quad$ Contribuição Social sobre o Lucro Líquido;

$\checkmark$ Contribuição do Programas de Integração Social e de Formação do Patrimônio do Servidor Público e Contribuição para Financiamento da Seguridade Social;

$\checkmark \quad$ Contribuição para o Instituto Nacional de Seguro Social;

$\checkmark \quad$ Fundo de Garantia de Tempo de Serviço;

$\checkmark \quad$ Imposto sobre Operações Financeiras;

$\checkmark \quad$ Imposto sobre Circulação de Mercadorias e Serviços;

$\checkmark \quad$ Compensação Financeira pela Exploração de Recursos Minerais;

$\checkmark \quad$ Participação do Superficiário (Proprietário do Solo);

$\checkmark \quad$ Taxa anual por hectare.

Vale destacar que no estado do Pará temos outras taxas pagas pelas empresas do setor mineral, como: a Taxa de Controle, Acompanhamento e Fiscalização das Atividades de Pesquisa, Lavra, Exploração e Aproveitamento de Recursos Minerários - TFRM instituída pela Lei n ${ }^{\circ}$ 7.591, de 28 de dezembro de 2011 (PARÁ, 2011); e, ainda, a Taxa de Controle, Acompanhamento e Fiscalização de Atividades de Exploração 
e Aproveitamento de Recursos Hídricos - TFRH, instituída pelo Decreto $n^{\circ} 1.227 / 2015$, regulamentando a Lei Estadual nº 8.091/2014 (PARÁ, 2015).

Em 2020, o Governo do Pará publicou a Lei Complementar n 133, que trata dos recursos destinados ao estado do Pará, fruto da Compensação Financeira pela Exploração de Recursos Minerais - CFEM, ficam reservados pelo menos $20 \%$ (vinte por cento) a serem aplicados em atividades relativas à diversificação econômica, ao desenvolvimento mineral sustentável e ao desenvolvimento científico e tecnológico, como prevê Lei Federal n 8.001, de 13 de março de 1990. Deste percentual estabelecido, $75 \%$ serão revertidos para o desenvolvimento da Ciência, da Tecnologia e da Inovação Tecnológica, bem como apoiar a formação profissional no Estado, vedado o uso dos recursos para pagamento de pessoal; e 25\% para a promoção e apoio a Startups, micro e pequenas empresas inovadoras elou de base tecnológica (AGÊNCIA PARÁ, 2020).

Pelo Projeto de Lei Complementar aprovado, os recursos destinados ficarão sob responsabilidade da Secretaria de Estado de Ciência, Tecnologia, Educação Profissional e Tecnológica (SECTET) e deverá estar em consonância com os planos plurianuais e os orçamentos anuais do estado.

No município de Canaã dos Carajás foi criado pela Lei n 834/2018 o Fundo Municipal de Desenvolvimento Sustentável (FMDS), que faz parte do projeto "Pacto por Canaã" da Prefeitura Municipal. A iniciativa destina $5 \%$ do valor da Compensação Financeira pela Exploração de Recursos Minerais (CFEM) para investimentos em negócios de diferentes áreas. Os valores podem ser utilizados na implantação, expansão, modernização e diversificação das atividades econômicas no município.

Segundo dados da ANM (2021), o município de Canaã dos Carajás arrecadou R $\$ 1,198$ Bilhão em 2020, sendo o segundo município com maior arrecadação de CFEM do Brasil, representando aproximadamente $20 \%$ do total. Apesar da expressiva arrecadação do município ainda é grande o desconhecimento do que seja a CFEM, a que se destina e como essa receita pode melhorar a vida da população.

Tal fato se constata na fala de $100 \%$ dos entrevistados que demonstram baixo conhecimento sobre a noção de os quais os critérios que foram adotados para o uso desses recursos, o que possivelmente pode ser em decorrência da baixa participação da sociedade em reuniões e assembleias legislativas do município e, também, ao pouco domínio sobre os direitos a eles ofertados.

Um dos entrevistados sugere que haja diálogo entre as partes para decidirem de forma conjunta o destino desse recurso, conforme trecho do entrevistado E18:

"É, acho que precisa ter uma instrução, uma conversa, né, de comunidade pra poder ouvir e distribuir melhor. Às vezes tá ali concentrada em determinada área, determinado seguimento, que às vezes não beneficia tanto a comunidade, as comunidade, e ás vezes eles acham que estão beneficiando, né? Mas por não ter esse momento de ouvir a comunidade sempre, de sentar, conversar, discutir e tá faltando esse elo, esse diálogo" (E18).

Quando perguntados se consideram que esses benefícios financeiros recebidos pela prefeitura por meio da atividade de mineração são suficientes, $72 \%$ afirmam que "Sim" e outros $28 \%$ disseram que "Não". Deve-se levar em consideração o dado expressivo dos entrevistados que não concordam que esses recursos são suficientes, pois como é perceptível no conteúdo das entrevistas esse entendimento é decorrente da falta de esclarecimentos sobre o recurso. 
A CFEM constitui-se como uma das principais fontes de recursos para as cidades, entretanto recursos originários dela não podem ser aplicados pelas administrações para pagamento de salários e de dívidas das prefeituras. Apresenta relevância essencial, logo, a delineação da utilização dessa fonte de receita para conceder as melhorias primordiais na prestação de serviços públicos à comunidade e a concepção e execução de projetos que objetivem à diversificação da economia local, tendo em vista o atributo finito da produção mineral.

\section{Considerações Finais:}

A mineração constitui um setor fundamental para a economia brasileira e do Pará e, por sua vasta aplicação, seria inviável pensar na vida moderna como a conhecemos e o avanço tecnológico mundial, pois dependem diretamente da mineração. Como um dos setores básicos da economia, a mineração pode contribuir, decisiva e positivamente, para o bem-estar e a melhoria da qualidade de vida das atuais e futuras gerações. Isso, evidentemente, desde que haja responsabilidade social pautada nos preceitos do Desenvolvimento Sustentável.

A exploração dos recursos minerais é uma atividade de uma rigidez locacional, mas, a forma e a tecnologia implementada na sua extração, é um campo de debate muito importante no cenário socioambiental do Brasil.

Os dados revelam a percepção dos cidadãos que vivem no município de Canaã dos Carajás em relação às ações sociais e ambientais da empresa de mineração que atua na região e sinaliza para a necessidade de efetiva implementação de práticas de responsabilidade e inclusão social.

Deve-se questionar a respeito de como a empresa gostaria de ser lembrada, de qual é o seu propósito, já que tem o comprometimento de deixar um legado naquele município e, como empresa, que deve ser cidadã, tem um compromisso muito maior com esse social, que seja estar delineado em programas de ação social como também discutir mais a fundo o seu papel dentro da sociedade, tendo objetivos prioritários dos investimentos mais estruturados e de longo prazo.

Esse olhar social é extensivo ao poder público, que também não demostra praticar formas de gestão participativa. Conforme sinalizam os entrevistados, embora tenham conhecimento do pagamento de tributos pela exploração mineral e bem sabem da importância de uma boa gestão e destinação destes recursos, desconhecem a existência de plano formalizado de aplicação dos recursos financeiros advindos da atividade mineral. Eles também demonstram desconhecer os critérios que são adotados para o uso dos recursos financeiros; a previsão de forma de participação direta da comunidade na tomada de decisões, assim como outros tipos de benefícios que o município recebe da atividade de mineração.

Há que considerar que o poder público tem parcela importante no processo de desenvolvimento das comunidades, o que não pode ser assumido apenas pelas corporações. É preciso que cada ator ocupe seu lugar. Assim, o relacionamento entre as mineradoras e as comunidades é um trabalho constante, que deve acompanhar toda a vida do projeto, desde o início até o encerramento da atividade mineral.

A influência da herança histórica das técnicas minerárias rudimentares desde o Brasil Colônia, as ações de garimpos irregulares que destroem o ambiente e até mesmo falsos empresários que trabalham à margem da lei são fatores que abrem espaço para que o cidadão possa ter uma percepção equivocada da mineração.

Dado isso, as informações obtidas, neste artigo, foram representadas utilizando codificações, tendo como principal benefício o demonstrativo para empresas, poder público e população se apropriarem desse conhecimento de forma a esclarecer para os leitores essa visão generalizada do setor mineral, já que assim 
como qualquer outra atividade antrópica gera impacto em diversas escalas. Vale ressaltar que é preciso considerar as circunstâncias (histórias, geográficas, econômicas, educacionais e culturais, entre outras) específicas de outras experiências e realidades de cada empreendimento/projeto minerário.

Com as constantes ameaças aos recursos ambientais, pesquisas que abordem a temática são cada vez mais importantes. Assim, esta pesquisa finaliza com a certeza de que possa inspirar novos estudos sobre projetos de mesma magnitude, como observado no município de Canaã dos Carajás, no Pará, e que está localizado em área sensível e estrategicamente importante, a Amazônia Legal.

\section{Referências:}

AGÊNCIA PARÁ. Acordo garante R\$ 102 milhões em investimentos no Territórios pela Paz. Notícia. 2019. Disponível em: < https://agenciapara.com.br/noticia/15047/> Acesso em: jun. 2020.

Governo publica a Lei que destina recursos da mineração para ciência e tecnologia. Notícia. 2020. Disponível em: <https://agenciapara.com.br/noticia/23301/> Acesso em: nov. 2020.

ANDRADE, José Guedes de. Competitividade na exploração mineral: um modelo de avaliação. Tese (Doutorado em Engenharia Mineral), Universidade de São Paulo, São Paulo, SP, 2001.

ANM. Agência Nacional de Mineração. Maiores Arrecadadores CFEM. Disponível em: <https://sistemas.anm.gov.br/arrecadacao/extra/relatorios/cfem/maiores_arrecadadores.aspx> Acesso em: mai. 2021.

BARDIN, Laurence. Análise de Conteúdo. Tradução: Luís Augusto Pinheiro. São Paulo: Edições 70, 2016.

BERARDI, P. C. Fatores indutores à evolução da gestão ambiental na indústria: uma abordagem pela Teoria Institucional. Tese (Doutorado em Administração de Empresas) - Escola de Administração de Empresas de São Paulo, Fundação Getúlio Vargas, São Paulo, 2012.

BRASIL. Lei № 13.540 de dezembro de 2017. Diário Oficial da República Federativa do Brasil. Disponível em: <http://www.planalto.gov.br/ccivil_03/_Ato2015-2018/2017/Lei/L13540.htm.> Acesso em: jun. 2020.

Decreto № 9.407 de 12 de junho de 2018. Diário Oficial da República Federativa do Brasil. Disponível em: <http://www.planalto.gov.br/ccivil_03/_Ato2015-2018/2018/ Decreto/D9407.htm.> Acesso em: jun. 2020.

COSTA, R. Rompimentos de barragens de mineradoras tem que se tornado mais graves nas últimas décadas. Brasil de Fato, 2015. Disponível em: <https://www.brasildefato.com.br/ node/33496/> Acesso em: jun.2020.

CORMICK, G. et al. Building consensus for a sustainable future: putting principles into practice. Ottawa: National Round Table on the Environment and the Economy, 1996. 136 p.

DALLARI, Pedro B. de Abreu. Institucionalização da participação popular nos municípiosbrasileiros. Instituto Brasileiro de Administração Pública, Caderno n. 1, p. 13-51, 1996.

DIÁRIO DO PARÁ. Pará lidera ranking de exportações minerais. Disponível em: <https://www.diarioonline.com.br/noticias/para/624148/para-lidera-ranking-de-exportacoes-minerais> Acesso em: abr.2021

EL PAís. O medo de uma cidade sob o risco de mais um 'tsunami' de lama. Notícia. 2019. Disponível em: $<$ https://brasil.elpais.com/tag/rompimiento_presa_brumadinho> Acesso em: mar.2020. 
ENRÍQUEZ, Maria Amélia R. da S. Maldição ou Dádiva? Os dilemas do desenvolvimento sustentável a partir de uma base mineira. f. 449. 2007. Tese (Doutorado em Desenvolvimento Sustentável) - Universidade de Brasília, Brasília, DF. 2007.

FARIAS, Carlos Eugênio Gomes. Mineração e Meio Ambiente no Brasil. Relatório preparado para o CGEE, PNUD - Contrato 2002/001604. Disponível em: <http://www.cgee.org.br/arquivos/estudo011_02.pdf>. Acesso em: mai. 2020.

FERNANDES, F. R. C.; LIMA, M. H. M. R.; TEIXEIRA, N. da S. Grandes minas e comunidades: algumas questões conceituais. Série Estudos e Documentos. CETEM/MCT, Rio de Janeiro, RJ. 2007.

FRANKS, D. M. et al. Conflict translates environmental and social risk into business costs. Proceedings of the National Academy of Sciences of the United States of America. v. 111, n. 21, p. 7576-7581, 2014.

FURTADO, C. Formação econômica da América Latina. Rio de Janeiro - RJ: Lia, 1969.

GAVIRIA, Edwin Muñoz. A "licença social para operar" na indústria da mineração: uma aproximação a suas apropriações e sentidos. Revista Brasileira de Estudos Urbanos e Regionais. v. 17, n. 2, p. 138-154, 2015.

GODARD, O. A gestão integrada dos recursos naturais e do meio ambiente: conceitos, instituições e desafios de legitimação. In: VIEIRA, P.

IBGE. Instituto Brasileiro de Geografia e Estatística. Portal das Cidades. Disponível em: < https://cidades.ibge.gov.br/brasil/pa/canaa-dos-carajas/pesquisa/38/47001?tipo =ranking\&indicador=47007 > Acesso em: mai. 2021.

HIRSCHMAN, Albert. Transmissão inter-regional e internacional do crescimento econômico. In: SCHWARTZMAN, Jacques. Economia regional: textos escolhidos. Belo Horizonte - MG: Cedeplar, p. 3552, 1977.

JEBER A.; PROFETA A.L. Recursos Minerais de Minas Gerais - Meio Ambiente e Mineração. Disponívelem:<http://recursomineralmg.codemge.com.br/wpcontent/uploads/2018/10/MAMineracao.pdf> Acesso em: mar. 2020.

JIJELAVA, D., \& VANCLAY, F. (2014). Social licence to operate through a gender lens: the challenges of including women's interests in development assistance projects. Impact Assessment and Project. Appraisal, 32(4), 283-293.

MANCINI, L.; SALA, S. Social impact assessment in the mining sector: Review and comparison of indicators frameworks. Resources Policy, v. 57, n. January, p. 98-111, 2018.

McALLISTER, M.L.; ALEXANDER, C.J. A stake in the future. Vancouver: UBC Press, 1997. 224p.

MITCHELL, B. Resource and environmental management. Harlow: Longman, 1997. 298 p.

MORAES, Roque. Análise de conteúdo. Revista Educação, Porto Alegre, v. 22, n. 37, p. 7-32, 1999.

ONU. Declaração sobre o Direito ao Desenvolvimento. Assembleia Geral das Nações Unidas. Disponível em: $\quad$ http://pfdc.pgr.mpf.mp.br/atuacao-e-conteudos-de-apoio/legislacao/direitoshumanos/decl_direito_ao_desenvolvimento.pdf> Acesso em: jun.2020.

PARÁ. Decreto N N 1.432, de 26 de novembro 2015. Diário Oficial do Estado do Pará. Disponível em: <https://www.sistemas.pa.gov.br/sisleis/legislacao/2864> Acesso em: jun. 2020.

PARÁ. Lei № 7.591, de 28 de dezembro de 2011. Diário Oficial do Estado do Pará. Disponível em: <https://www.legisweb.com.br/legislacao/?id=148084> Acesso em: jun. 2020.

PIOVESAN, Flávia. Temas de direitos humanos. [São Paulo]: M. Limound, 2000. 
PREFEITURA DE CANAÃ DOS CARAJÁS. Plano Local de Habitação de Interesse Social. Canaã dos Carajás, PA. 2014.

RICHARDSON, R. J. Pesquisa social: métodos e técnicas. São Paulo: Atlas, 1999.

SANTIAGO, Ana Lúcia Frezzatti. Licença Social para Operar e Avaliação de Impacto Social. Belo Horizonte: Letramento Editora e Livraria, 2019.

SEN, Amartya. Desenvolvimento como liberdade. São Paulo: Companhia das Letras, 2010.

SILVA, Alberto Rogério Benedito. A Indústria Mineral no Pará. Belém, 2012.

TANNO, L. C.; SINTONI, A. (Coords.). Mineração e município: bases para planejamento e gestão de recursos minerais. IPT. São Paulo

VANCLAY, F. Conceptualising Social Impacts. Environmental Impact Assessment Review, v. 22, n. 3, p. 183-211, 2002.

VIEIRA, PF.; WEBER, J. (Orgs.) Introdução geral: sociedades, natureza e desenvolvimento viável. In: P. F. Vieira e J. Weber (Orgs.). Gestão de recursos naturais renováveis e desenvolvimento: novos desafios para a pesquisa ambiental. São Paulo: Cortez, 2000, p. 17-49.

VIEIRA, PF. et al. Gestão integrada e participativa de recursos naturais: conceitos, métodos e experiências. Florianópolis: Secco/APED, 2005. 416p. 